\title{
Konstruksi Sosial Soft Masculinity dalam Budaya Pop Korea
}

\author{
Eka Perwitasari Fauzi \\ Program Studi Ilmu Komunikasi, Fakultas Ilmu Komunikasi, Universitas Mercu Buana \\ Jl. Meruya Selatan No 1, Kembangan, Jakarta, 11650, Indonesia \\ Corresponding author: eka.perwitasari@mercubuana.ac.id;
}

\begin{abstract}
Culture influences the meaning of the concept of masculinity through belief systems, values, and behavior. This study aims to explore Generation Y's point of view in viewing the concept of soft masculinity as opposed to hegemonic masculinity in Indonesia. The research method used is phenomenology with a qualitative approach. The data collection technique used semi-structured in-depth interviews with eight informants. The results showed that eight informants accepted the concept of soft masculinity through the social media mass construction process. The externalization process in the form of adaptation to the concept of gender occurs through media consumption. The objectification of the characteristics of tender charisma, politeness, and purity occurs when informants interact with the surrounding environment and local cultural values. The internalization of the concept of soft masculinity is in the form of acceptance of new masculinity values and is used as a new understanding in looking at the concept of masculinity. This social construction consists of three stages, namely externalization, objectivation, and internalization. This study strengthens the assumption that the media as a cultural agent has an important role in carrying out the social construction ofnew masculinity values. The substance of this research contributes in the form of recommendations for new concepts related to masculinity that are formed as a result of social construction by the media, and serves as a new perspective in viewing the concept of gender in society. Keywords: Gender Communication; Perception;Phenomenology; SoftMasculinity; Social ConstructionofMedia
\end{abstract}

\begin{abstract}
Abstrak
Budaya memengaruhi pemaknaan terhadap konsep maskulinitas melalui sistem kepercayaan, nilai-nilai dan perilaku. Penelitian ini bertujuan untuk menganalisis sudut pandang Generasi Y dalam memandang konsep soft masculinity yang bertentangan dengan hegemoni maskulinitas di Indonesia. Metode penelitian yang digunakan adalah fenomenologi dengan pendekatan kualitatif. Teknik pengumpulan data menggunakan teknik wawancara mendalam semi tersturuktur dengan delapan informan. Hasil penelitian menunjukkan bahwa delapan informan menerima konsep soft masculinity melalui proses konstruksi sosial media massa. Proses eksternalisasi berupa adaptasi dengan konsep gender terjadi melalui konsumsi media. Objektifikasi karakteristik tender charisma, politeness, dan purity terjadi ketika informan melakukan interaksi dengan lingkungan sekitarnya dan nilai budaya lokal. Internalisasi konsep soft maskulinity berupa penerimaan nilai maskulinitas baru dan dijadikan sebagai pemahaman baru dalam memandang konsep maskulinitas. Hasil penelitian ini memperkuat asumsi bahwa media sebagai agen budaya memiliki peran penting dalam melakukan konstruksi sosial nilai-nilai maskulinitas baru. Substansi penelitian ini memberikan kontribusi berupa rekomendasi terkait maskulinitas yang terbentuk sebagai hasil konstruksi sosial oleh media, dan dijadikan sebagai perspektif baru dalam memandang konsep gender di masyarakat.
\end{abstract}

Kata kunci: Komunikasi Gender; Persepsi; Fenomenologi; Soft Masculinity; Konstruksi Sosial

\section{Pendahuluan}

Studi tentang gender berkembang pesat dalam beberapa dekade belakangan. Gender merupakan hal penting dalam proses komunikasi. Song dan Velding (2020) berpendapat bahwa hal pertama yang diperhatikan oleh manusia ketika bertemu manusia lain adalah gender. Studi tentang gender mayoritas didasarkan pada akar feminisme yang membahas mengenai posisi wanita sebagai kaum yang termaginalkan di dalam masyarakat. Ratnasari et.al (2020) mengungkap bahwa perkembangan teknologi media baru menimbulkan masalah baru berupa Kekerasan Berbasis Gender Online (KBGO), dimana mayoritas objek penderita adalah wanita.

Studi mengenai laki-laki dan maskukinitas sebagai peran gender tidak terlalu banyak dikembangkan. Laki-laki dipandang sebagai individu yang memiliki posisi kuat di masyarakat sementara wanita dipandang sebagai objek. 
Barry (2018) menyatakan bahwa gender adalah pencapaian yang kontinyu. Gender dilihat sebagai sebuah pencapaian, sebuah interaksi sehari-hari yang memperkuat keberadaannya melalui aktivitas dan hubungan sosial individu (Coston \& Kimmel, 2012). Ada berbagai kajian teori sosiologi yang membahas mengenai transformasi terkini dalam perilaku, penampilan dan opini pria. Penelitian sejarah juga menunjukkan bahwa konsep maskulinitas terus berubah seiring dengan perubahan jaman (Bridges \& Pascoe, 2014).

Urgensi penelitian ini terletak pada proses pergeseran makna dari maskulinitas sebagai hasil interaksi sosial masyarakat dan teknologi media baru. Perubahan makna terjadi akibat transformasi masyarakat dari masyarakat industri menjadi masyarakat informasi. Bentuk komunikasi baru yang timbul akibat media baru memengaruhi ideologi gender dan praktik gender terutama di kawasan Asia (Louie, 2012).

Korea Selatan merupakan sebagai salah satu negara Asia Timur yang gencar melakukan ekspor tren budaya populer ke berbagai negara di dunia, tidak terkecuali negara-negara di Asia Tenggara termasuk Indonesia. Konsumsi budaya populer korea (selanjutnya disebut Hallyu) meningkat secara kontinyu di Indonesia sejak awal 2000-an (Jeong et al., 2017). Total ada sekitar 70 drama yang disiarkan oleh televisi swasta nasional pada tahun 2002-2011. Awal popularitas budaya Asia Timur dimulai sejak rezim Soeharto jatuh pada tahun 1998. Liberalisasi dan diversifikasi media di Indonesia memainkan peran kunci dalam distribusi Timur Budaya pop Asia. Sen dan Hill (2011) menyatakan media Indonesia berhasil keluar dari kekangan pemerintah otoriter dan di saat yang bersamaan muncul teknologi internet menciptakan ruang dan cara baru untuk mengakses media dimanapun.

Satu dekade belakangan budaya Korea Selatan menjadi salah satu perhatian peneliti sosial. Akhmad et al. (2018) meneliti tentang budaya pop korea memengaruhi remaja di Makassar. Hasil penelitian menunjukkan tren penggunaan media sosial yang tinggi oleh remaja untuk mencari informasi tentang idola favoritnya. Tidak hanya itu, media sosial juga digunakan untuk berkomunikasi dengan penggemar lain.

Ayuningtyas (2017) meneliti mengenai persepsi penggemar perempuan terhadap image soft masculinity yang ditampilkan oleh grup Idol laki-laki. Pada penelitian ini para informan sadar bahwa konsep soft masculinity yang ditampilkan oleh para idola laki-laki merupakan bagian dari strategi marketing. Di dunia industri hiburan, identitas gender lumrah untuk dimodifikasi dan merupakan bagian dari pertunjukan.

Hasil penelitian Putri dan Mintarsih (2020) menyatakan bahwa meskipun soft masculinity diterima oleh fans BTS di Amerika, namun, sebagian fans laki-laki masih memegang teguh prinsip laki-laki-hegemoni. Alam \& Nyarimun (2017) dalam penelitian yang dilakukan mengenai musik K-Pop digunakan sebagai bentuk diplomasi soft power Korea Selatan di Asia menemukan bahwa ekspansi budaya Korea yang terjadi secara masif selama beberapa tahun belakangan ini tidak lepas dari dukungan pemerintah Korea Selatan. Musik Kpop sebagai diplomasi modern memberikan kontribusi dalam perekonomian Korea Selatan utamanya di sektor pariwisata. Alokasi dana sebesar 1 persen juga dilakukan untuk pengembangan bisnis musik di Korea Selatan.

Penelitian yang dilakukan oleh Fauzi dan Nugraha (2020) mengungkap konsep Bromance yang tampilkan dalam Variety Show "Run BTS" di platform Vlive dengan menggali penerimaan audiens yang terdiri dari fans Kpop dan Non-fans dimana lima informan ada pada posisi oposisi. Hal ini berarti pemaknaan audiens tidak sejalan dengan pesan media. Menurut para informan interaksi Bromance dalam tayangan "Run BTS" dinilai berlebihan dan kurang pantas untuk kaum laki-laki. Penelitian lain yang dilakukan oleh Nisrina et al. (2020) menunjukkan bahwa budaya pop Korea dinilai sangat persuasif sehingga tanpa sadar memengaruhi gaya hidup anak 
muda yang dengan cepat mengikuti gaya hidup konsumerisme. Triartanto et al. (2020) melakukan penelitian mengenai diseminasi budaya pop untuk meningkatkan brand image dengan menggunakan selebritas pop Korea dalam produk e-commerce. Hasil penelitian tersebut menunjukkan bahwa tren program hiburan, iklan yang menggunakan selebritas asing merupakan sebuah fluktuasi program yang dapat tergantikan di masa depan. Penelitian Zakiah et al. (2019) mengenai mekanisme perubahan budaya melalui proses difusi, akulturasi, dan asimilasi. Hasil penelitian Zakiah menunjukkan bahwa media massa, utamanya media online, memiliki peran sentral dalam menyebarkan materi budaya berupa drama, musik, fashion, makanan, dan juga bahasa.

Semua studi tentang budaya pop Korea tersebut dilakukan pada komunitas penggemar dan pemanfaatan teknologi media baru untuk menganalisis efek teknologi baru terhadap perilaku masyarakat. Beberapa penelitian terdahulu mengenai budaya pop Korea dan gender memberikan gambaran mengenai pengaruh arus budaya dan kemajuan teknologi sebagai bentuk dari globalisasi sangat masif dan mampu mengonstruksi pemahaman seseorang, mengubah identitas budaya serta membangkitkan fenomena transbudaya (Fibrianto et al., 2020). Sulistyo et. al (2016) menyatakan bahwa gender sebagai hasil bentukan media, maknanya terus berubah. Kajian gender sebagai hasil konstruksi sosial media belum banyak dilakukan. Penelitian ini menggali perubahan makna gender dengan menggunakan konstruksi sosial media dari sudut pandang generasi milenial atau Generasi Y.

Generasi Y adalah individu yang lahir di tahun 1981 hingga 2000 dan diidentifikasikan sebagai digital native (Velasco, 2020). Generasi Y lahir dan tumbuh di era digital, dan dipandang sebagai generasi dengan tingkat literasi media yang tinggi. Prihantoro et. al (2020) mendefinisikan generasi Y sebagai individu yang memiliki kemampuan adaptasi yang tinggi terhadap teknologi komunikasi baru seperti telepon seluler, komputer, dan internet.
Sebuah polling yang dilakukan oleh Fusion pada tahun 2014 dan melibatkan 1000 orang berusia 18 hingga 34 tahun menyatakan bahwa $50 \%$ dari responden mengatakan bahwa gender adalah sebuah spektrum (Wong, 2015). Pandangan konvensional tentang perempuan dan laki-laki menjadi kabur dengan munculnya istilah androgini dan Gender Fluid yang mengacu pada identitas gender keduanya yang dianggap sebagai hal 'normal' oleh para Millennial (Friedman, 2017). Gender Fluid mengacu pada perubahan yang terjadi dari masa ke masa akan identitas gender seseorang (Katz-Wise, 2020). Seseorang dapat mendefinisikan dirinya sebagai perempuan, laki-laki, gabungan, atau bahkan tidak memiliki gender (Juniman, 2017).

Song dan Velding (2020) dalam penelitian terhadap sekitar 722 mahasiswa di Amerika Serikat, menyebutkan bahwa responden secara sosial mengonstruksikan perbedaan citra laki-laki Asia yang direpresentasikan oleh anggota Idol grup laki-laki K-pop dengan tipe maskulin ideal di Amerika. Hasil survei menyebutkan bahwa para anggota boyband K-Pop tersebut sangat tidak maskulin dilihat dari segi penampilan, misalnya badan yang kecil, kulit yang tampak lembut terawat, dan klimis tanpa bulu wajah. Narasi ini mirip dengan gambaran stereotip lakilaki Asia di Amerika Serikat pada umumnya. Temuan ini menandakan potensi perubahan konsep maskulinitas melalui interkoneksi budaya dalam konteks global (Song \& Velding, 2020).

Bentuk dominasi dari budaya populer dari Asia Timur, budaya Hallyu memiliki kontribusi yang signifikan dalam merubah konsep maskulinitas di kawasan Asia Tenggara (Ainslie, 2017). Jin (2019) dalam penelitiannya mengungkapkan bahwa pertumbuhan budaya pop Korea belakangan ini telah memicu diskusi tentang transnasionalisasi budaya pop ke level yang baru. Hallyu dianggap memiliki peran kunci dalam menggeser peta budaya yang sebelumnya didominasi oleh negara-negara barat, seperti Amerika Serikat dengan gaya produksi blockbuster (Jin, 2019). 
Data dari Global Korean Wave 2016 menunjukkan ada sekitar 1.652 komunitas Hallyu yang terdiri dari 59.390.000 anggota yang tersebar di 88 negara di seluruh dunia. Di wilayah Asia Pasifik sendiri pertumbuhan penggemar Hallyu meningkat dari 20 juta menjadi 40,1 juta (Jang \& Song, 2017). Kebangkitan Hallyu, tidak bisa dilepaskan dengan perkembangan media digital terutama media sosial seperti Youtube dan aplikasi User-generated Content (UGC) lainnya (Oh \& Lee, 2014). Internet memiliki peran besar dalam perkembangan grup Idol Korea Selatan. Di masa sekarang, masyarakat memiliki kecenderungan untuk bergantung pada internet untuk berkomunikasi dan juga sebagai kunci penting dalam mengakses informasi (Tresnawati \& Ibrahim, 2020). Fans global yang tergabung dalam fandom-fandom online dengan cepat menjadi elemen penting dalam memengaruhi popularitas global grup-grup Idol tersebut.

Penelitian Kusuma et al. (2020) menyimpulkan bahwa fandom global berperan sebagaiagen sosial dimanatidak hanya melakukan interaksi termediasi melalui komunitas di media sosial online tetapi juga melakukan berbagai gerakan sosial seperti kegiatan amal dan juga kegiatan offline seperti "Nonton Bareng". Puncak popularitas Hallyu ditandai dengan munculnya "Gangnam Style" oleh PSY pada akhir 2012. Song (2020) berargumen pemerintah Korea Selatan memberikan dukungan penuh terhadap industri budaya sebagai upaya ekspansi imperalisme budaya (Appadurai, 2016; Jung, 2019; Kwon \& Kim, 2014). Fase ini kemudian disebut sebagai Hallyu 2.0, New Korean Wave (Jin \& Yoon, 2016; S. Lee \& Nornes, 2015), Neo Hallyu atau Hallyuwood (Elaskary, 2018).

Korea memadukan ajaran konfusianisme yang sangat kental dengan budaya kontemporer barat, hal inilah yang menjadikan budaya Korea unik. Konsep ini disebut sebagai Glocalization yaitu proses percampuran (hybrid) budaya lokal dan budaya global (Lee et al., 2020). Konsep
Hybrid Culture sejalan dengan argumen Coston dan Kimmel (2012) bahwa norma sosial dapat menjadi identitas personal individu. Percampuran dua nilai budaya terjadi melalui proses yang intim dengan segala seluk beluk aktivitas komunikasi sehari-hari sehingga identitas gender diakui secara sah dan 'sesuai' dengan norma budaya tersebut.

Maskulinitas merupakan konsep yang terdiri dari perilaku (behaviour), bahasa (language), dan praktik (practices) dalam tempat-tempat kelompok budaya yang spesifik. Konsep maskulinitas umumnya diasosiasikan dengan laki-laki dan didefinisikan secara cultural sebagai "non-feminin", sehingga maskulinitas dan perilaku laki-laki bukanlah produk sederhana dari kode genetik atau predisposisi biologi (Itulua-Abumere, 2013).

Baker dan Levon (2016) mengungkapkan bahwa konsep maskulinitas laki-laki tidak bisa dijelaskan dengan hanya satu definisi saja. Ada berbagai definisi "kelaki-lakian" (manhood) dalam konteks sejarah dan sosial. Beberapa definisimerujukpadadominasibudayadanpolitik. "Laki-laki" berkaitan dengan imperialisme dan hegemoni budaya yang berpengaruh terhadap bagaimana individu memandang dirinya sebagai laki-laki yang sesuai dengan konsep dominan maskulinitas yang ada dalam budaya masyarakatnya. Connell (2016) berpendapat bahwa hegemoni selamanya akan terus ada pada status dinegosiasi, renovasi, dan kontestasi.

Konsep baru tentang laki-laki (new man) muncul di tahun 80-an, dengan merujuk pada karakteristik laki-laki yang lebih sensitif, perhatian, anti-seksisme, serta lebih peduli pada penampilan fisik dan dengan sukarela berbagi kegiatan domestik yang biasanya lekat pada wanita (Baker \& Levon, 2016). Konsep ini muncul untuk menentang steretotipe tentang laki-laki yang umumnya diasosiasikan dengan perilaku agresif, sifat egois, dan ketidakpedulian (Veissière, 2018). Stereotipe laki-laki ini mengalami perubahan dalam dua dekade 
terakhir. Akibat krisis ekonomi tahun 1997, Korea Selatan mulai menampilkan citra lakilaki yang lebih lembut dengan penampilan yang sederhana, perhatian (good listener), tidak malu melakukan pekerjaan yang biasanya dilakukan wanita dan fashionable (Maliangkay, 2013).

Ikon laki-laki ini disebut sebagai "kkonminam" (Jung, 2011; Khai \& Wahab, 2017; Maliangkay, 2013). Istilah ini merupakan perpaduan dari dua kata dalam bahasa Korea yaitu "Kkot" yang artinya "bunga", dan " $M i$ nam" yang berarti "laki-laki yang cantik". Secara keseluruhan Kkonminam berarti laki-laki yang berpenampilan menarik seperti bunga" (Song \& Velding, 2020) atau populer dengan sebutan Flower Boy, pretty boys atau soft boys.

Jung (2011) berpendapat bahwa kkonminam dapat memuaskan hasrat kompleks manusia karena mereka memiliki karakteristik maskulin (tubuh tinggi) sekaligus feminin (kulit yang putih dan halus, rambut yang lembut seperti sutra, perilaku yang lembut dan romantic). Beberapa tahun belakangan, gagasan mengenai "beautiful man" memiliki cakupan yang cukup luas dalam konteks pemaknaan, terutama di wilayah Asia Timur melalui budaya popular dari China, Jepang dan Korea (Louie, 2012). Konsep Soft masculinity di Korea merupakan percampuran antara Seonbi (konsep maskulinitas tradisional Korea), Bishounen (konsep pretty boy Jepang) dan Global Metroseksual. Konsep hybrid ini yang membuat soft masculinity dapat diterima di berbagai belahan dunia (Jung, 2011).

Istilah soft boys, flower boys, soft masculinity, muncul sebagai bentuk pengaruh dari proses diseminasi nilai transkultural melalui media. Louie (2012) berpendapat bahwa gagasan tentang soft masculinity muncul seiring dengan meningkatnya daya beli wanita dan anak muda, yang merupakan kelompok pengguna aktif internet dan menikmati konten- konten K-pop yang disajikan melalui media sosial misalnya Youtube yang membuka peluang bisnis baru bagi industri musik K-Pop (Lee et al., 2020; Louie, 2012; Oh \& Lee, 2013).

Gagasan mengenai konsep "soft masculinity" mulai diterima di Indonesia. Ukuran maskulinitas laki-laki tidak lagi melulu soal laki-laki berotot. Lelaki feminin dengan perilaku yang memakai produk kecantikan khusus pria (men's grooming) secara perlahan diterima oleh masyarakat (Nurhadi, 2018).

Jung (2011) menuangkan gagasan Soft masculinity melalui sosok Bae Yong Joon, aktor Korea yang menjadi pencetus demam pretty boy di Kawasan Asia pada awal 2000-an. Ada tiga karakteristik menonjol dari Soft masculinity yaitu Tender Charisma, Politeness, dan Purity.

Tender Charisma artinya bicara mengenai kombinasi antara sisi laki-laki yang diasosiasikan dengan watak yang tegas dan sisi lembut yang dimiliki wanita. Adegan laki-laki menangis menjadi salah satu ciri khas yang banyak ditemui dalam drama Korea (Khai \& Wahab, 2017). Purity berarti bicara mengenai penggambaran cinta polos dan lugu (innocent) yang mengingatkan penonton pada cinta pertama mereka di masa muda. Politeness merupakan karakteristik ketiga dimana Jung menggambarkan seorang laki-laki yang penuh dengan adab yang baik, santun, dan perhatian terhadap lawan jenis. Hal ini sangat bertolak belakang dengan potret lakilaki di masa lalu, dimana laki-laki dicitrakan sebagai pribadi yang kasar dan otoriter.

Gagasan "hybrid masculinity" menandakan bahwa konsep maskulinitas bukan hal yang bersifat statis tapi sebuah wujud transformasi dari performa gender (Messner, 2007). Bridges (2014) mengagas bahwa konsep hybrid masculinity telah menjadi sebuah fenomena sosial yang signifikan di masa sekarang (Bridges, 2014). 
Penelitian ini melakukan analisis dengan menggunakan teori Konstruksi Sosial Realitas. Teori ini didefinisikan sebagai proses sosial melalui tindakan dan interaksi dimana individu atau sekelompok individu, menciptakan secara terus-menerus suatu realitas yang dimiliki dan dialami bersama secara subjektif (Kusuma et al., 2020; Nurhadi, 2018). Dengan kata lain, satu objek akan dipandang sama dan dimaknai sama oleh anggota masyarakat dari kultur yang sama (Morissan et al., 2015).

Individu aktif dalam menciptakan sebuah realitassosial.Realitasmerupakanhasilkonstruksi sosial manusia. Manusia memiliki kebebasan untuk bertindak di luar aturan sistem sosial sesuai dengan apa yang diinginkan. Realitas sosial merupakan entitas yang berdiri di luar individu, misalnya media. Media membentuk realitas sosial dan menyajikan dalam bentuk konten pesan.

Penelitian ini melihat media bukan hanya saluran yang netral. Media dilihat sebagai subjek yang aktif melakukan konstruksi realitas, berikut sudut pandang, bias dan pemihaknya. Hal tersebut sesuai dengan penelitian yang dilakukan Santoso (2016) mengenai media aktif menafsirkan realita untuk disajikan kepada khalayak. Sejalan dengan perkembangan jaman, manusia terus menerus menegosiasikan makna gender sesuai dengan lingkup sosial yang ada.

Media sebagai salah satu agen sosialisasi memiliki kontribusi terhadap konstruksi realitas gender. Realitas gender merupakan hasil pemikiran manusia melalui proses interaksi dengan dunia sosial termasuk media. Gender sebagai realitas merupakan hasil konstruksi manusia. Manusia sebagai mahluk dengan tingkat keingintahuan yang tinggi mendapatkan makna melalui tiga proses dialektika yaitu eksternalisasi, objektivasi, dan internalisasi.

Penelitian ini bertujuan untuk menganalisis konsep soft masculinity yang dikonstruksikan oleh budaya melalui media. Penelitian ini menggali sudut pandang Generasi Y dalam memandang konsep soft masculinity yang bertentangan dengan hegemoni maskulinitas di Indonesia.

\section{Metode Penelitian}

Penelitian ini merupakan penelitian deskriptif kualitatif yang menekankan pada sudut pandang informan dengan menggunakan pendekatan konstruktivisme. Penelitian ini menggunakan metode penelitian fenomenologi dengan menggali makna berdasarkan pengalaman subjek penelitian.

Subjek penelitian ini adalah Generasi Y dengan alasan generasi ini merupakan individu dengan paparan tinggi terhadap teknologi media baru. Objek penelitian ini adalah drama Korea, musik Kpop, dan produk kecantikan Korea.

Pengambilan data dalam riset ini menggunakan teknik purposive sampling. Kriteria informan yang diambil adalah generasi Y (lahir antara 1981-1994), mengikuti perkembangan budaya populer Korea, dan memiliki pemahaman mengenai konsep gender.

Pengambilan data pada penelitian ini menggunakan teknik wawancara mendalam dengan jenis wawancara semi-terstruktur. Penelitian ini mengambil delapan (8) orang informan yaitu dua laki-laki, dimana Informan 5 (GO) merupakan pekerja di sebuah klinik kecantikan dan menggunakan produk kecantikan dalam kesehariannya, sementara Informan 1 (DDR) yang merupakan mahasiswa tingkat akhir adalah bukan penggemar Kpop namun familiar dengan tren produk kecantikan lakilaki yang populer di kalangan anak muda. Enam orang wanita sebagai informan dipilih dengan latar belakang sosial berbeda. Mayoritas informan wanita familiar terhadap budaya pop Korea, tidak hanya musik, drama, makanan, tetapi juga pengalaman interaksi di media sosial. Empat di antaranya adalah penggemar grup idol Korea, sementara dua informan adalah penggemar drama Korea. Nama informasn disamarkan untuk melindungi privasi. Data informan dapat dilihat pada Tabel 1.

Teknik analisis data yang dilakukan dalam penelitian menggunakan teknik dari Miles, Huberman, dan Saldana. Teknik ini terdiri dari 
Tabel 1. Data Informan

\begin{tabular}{ccccc} 
No. & Kode Informan & Jenis Kelamin & Umur & Pekerjaan \\
\hline 1 & DDR (Informan 1) & Laki-laki & 23 thn & Mahasiswa \\
2 & RTH (Informan 2) & Perempuan & 24 thn & Karyawan \\
3 & RNT (Informan 3) & Perempuan & 30 thn & Karyawan \\
4 & CHY (Informan 4) & Perempuan & 22 thn & Mahasiswa \\
5 & G0 (Informan 5) & Laki-laki & 25 thn & Karyawan \\
6 & IND (Informan 6) & Perempuan & 35 thn & Ibu rumah tangga \\
7 & WND (Informan 7) & Perempuan & 30 thn & Karyawan \\
8 & GTA (Informan 8) & Perempuan & 38 thn & Karyawan \\
\hline
\end{tabular}

Sumber: Data Peneliti (2020)

reduksi data yang terkait konsumsi budaya korea berupa serial drama televisi, musik pop korea, dan produk kecantikan korea, kemdian data disajikan dan diverifikasi dengan ditarik kesimpulan. Data dianalisis berdasarkan momen dialektis dalam teori konstruksi realitas sosial media dari Berger dan Luckman.

\section{Hasil Penelitian dan Pembahasan}

Pengumpulan data dilakukan melalui wawancara mendalam dengan delapan informan. Hasil wawancara merupakan data primer yaitu berupa pengalaman dalam memaknai soft maskulinity. Data kemudian dibagi menjadi tiga kategori berdasarkan konsep soft masculinity yaitu Tender Charisma, Politeness, dan Purity (innocent). Hasil penelitian kemudian dianalisis dengan menggunakan tiga momen dialektis dari teori konstruksi realitas sosial Berger dan Luckman, yaitu Eksternalisasi, obyektivasi, dan internalisasi.

\section{Eksternalisasi Soft masculinity}

Proses eksternalisasi adalah momen adaptasi diri yang mencakup proses penyesuaian terhadap sebuah ide gagasan budaya sebagai produk manusia. Pada penelitian ini dunia sosio kultural mendefinisikan maskulinitas sebagai lelaki yang tangguh, pekerja keras dengan menonjolkan bentuk fisik berotot dan utamanya melambangkan dominasi terhadap wanita.
Perilaku, penampilan seorang laki - laki yang tidak sesuai dengan kategori hegemoni maka dianggap tidak masuk ke dalam konsep laki-laki macho artinya karena dianggap tidak macho maka dianggap menyimpang. Hal ini juga dijabarkan oleh para informan yang mengatakan bahwa penampilan fisik bukan menjadi tolok ukur "kenjantanan" seorang laki-laki. Informan 1 menyatakan bahwa lakilaki saat ini lebih memperhatikan penampilan. percaya bahwa pemakaian produk kecantikan lebih didasarkan pada alasan kesehatan: "yang penting rapi dan jujur apa adanya. Cowok yang bersih, rapi pakai skin care sebenarnyanggakmasalahkarenauntukalasan menjaga Kesehatan" (Informan 1, Juli 2020). Grooming menjadi hal yang normal dilakukan oleh laki-laki. Sebaran nilai-nilai budaya yang ada di dalam media menyebabkan peningkatan kesadaran akan produk kecantikan asal Korea tidak hanya bagi wanita saja tetapi juga bagi laki-laki. Selaras dengan hasil penelitian oleh Triartanto et al. (2020) dimana di Indonesia sendiri penggunaan selebritas Korea Selatan sebagai brand ambassador oleh para produsen merupakan salah satu trik marketing untuk menarik para penggemar fanatik. Para informan berargumen bahwa perawatan wajah seharusnya tidak dikaitkan dengan gender. Laki-laki dengan masalah kulit maka akan diberikan perawatan yang sama dengan wanita yang punya masalah kulit. 
“...it's about time! Sudah waktunya lakilaki dan wanita sama-sama jadi terawat. Sama-sama manusia dengan kulit yang sama, kenapa skincare hanya dibatasi untuk perempuan saja? Padahal lakilaki juga mengalami masalah (kulit) yang sama..." (Informan2, Juli 2020) Informan 2 menambahkan bahwa sudah saatnya laki-laki juga harus memperhatikan dirinya dan tidak perlu malu dengan pemberian label "kurang macho". Informan 2 mengatakan bahwa dirinya saat ini lebih menyukai citra laki-laki Asia dibandingkan dengan citra laki-laki yang disuguhkan oleh budaya barat. Informan 2 menambahkan bahwa dirinya justru tertarik dengan laki-laki yang tidak malu untuk menunjukkan sisi lemahnya. “...soft boys, bukan artinya gay. Saya secara pribadi lebih suka cowok yang gentle, sweet. Di kantor, teman-teman cowok saya semua straight (bukan gay). Ketika ada sesi sharing jujur (tentang perasaan selama kerja bareng) mereka tidak malu untuk pelukan (ketika meminta maaf), saling comfort, dan ini malah bikin saya merasa tersentuh..." (Informan 2, Juli 2020)

Stereotipe tentang laki-laki yang dingin, cuek, dan egois didobrak oleh pendapat Informan 2. Sikap dan perilaku yang disampaikan oleh Informan 2 menjelaskan bahwa laki-laki tidak selamanya cuek dan berhati dingin. Hanya saja memperlihatkan sisi feminine ketika melakukan sesisharingyangbiasanyadigelarolehperusahaan untuk meningkatkan sense of belonging di antara karyawan. Informan 2 menggambarkan bahwa laki-laki tidak selalu memiliki kesan dingin, egois dan cuek. Kelembutan hati mereka tercermin dalam bentuk pelukan dan katakata yang menenangkan (comforting). Hal ini justru membuat Informan 2 merasa tersentuh.

Informan 7 mengatakan hal serupa dimana hubungan antara anggota grup idol laki-laki terlihat murni kasih sayang antar saudara yang penuh kepolosan. “...mereka (idol laki-laki) mengingatkan saya sama teman-teman kuliah saya dulu. Perbedaannya mungkin interaksi mereka terlihat free dibandingkan cowok-cowok seumuran mereka di Indonesia. Maksudnya interaksi skinship yang mereka lakukan itu seperti lumrahnya yang dilakukan oleh anak-anak kecil di sini. Coba saja perhatikan anak-anak TK (taman kanakkanak), mana ada gengsian gandengan antara anak cowok sama anak cowok, rangkul-rangkulan, atau glendotan sama temannya. Kelihatan pure, murni temenan, juga sama fans..." (Informan 7, Juli 2020) Informan 7 menganggap laki-laki Korea lebih bebas dalam berekspresi termasuk menunjukkan kasih saying tidak hanya ke lawan jenis tapi juga sesama laki-laki dalam konteks pertemanan atau persaudaraan. Kebebasan berekspresi ini berbentuk kontak fisik (skinship) yang tidak ragu untuk ditunjukkan oleh sesama idola laki-laki Korea Selatan. Kontak fisik ini seperti lumrahnya yang dilakukan oleh anak-anak yang lugu, tidak ada tujuan seksual ketika bergandengan tangan, atau berpelukan. Interaksi fisik, termasuk kepada fans, terlihat murni berteman.

Informan 8 mengatakan hal serupa dimana para aktor dan Idol Korea tidak segan memperlihatkan gestur lucu yang memberi kesan "imut"sepertimendeskripsikananak-anak. Hal ini dikarenakan Korea Selatan mengenal "aegyeo". "...nggak cuma fisik aja yang menarik. Cara mereka memperlakukan fans juga beda sama bintang film Hollywood. Mereka lebih deket, dan sangat menghargai fans. Down to earth banget, nggak sok. Mereka juga suka bikin gestur yang imut-imut, lucu, bikin gemes. Jadi orang kaya saya juga suka dan berubah pandangan bahwa cowok nggak selamanya harus berotot. Pun dari segi sikap, cowok yang lembut bukan berarti dia banci..." (Informan 8, Agustus 2020) Informan 8 mengatakan bahwa artis Korea memiliki kesan sopan, mungkin karena budaya Asia yang memang menjunjung tinggi kesopanan. Idol Korea juga dinilai lebih memperhatikan fans dibandingkan selebriti barat. Ada rasa kedekatan lebih membumi dan menghargai fans. 
Informan 7 berpendapat bahwa selama lakilaki memiliki perilaku dan sikap yang baik, sopan, punya pendidikan, penampilan yang feminin dirasa tidak ada masalah. Informan 5 mengatakan bahwa persepsi tentang konsep maskulin kembali kepada pribadi masingmasing. Indonesia menganut sistem patriarkis yang kuat oleh karena itu konsep soft masculinity pada awalnya dirasa kurang pas, sehingga budaya lokal memiliki peran penting dalam konstruksi ini. Informan 3 dan 6 juga mengatakan bahwa seorang laki-laki dianggap ideal jika memiliki kepribadian yang lembut, penyayang, tidak otoriter meskipun tidak menepis bahwa seorang laki-laki yang utama haruslah seorang pekerja keras yang menomorsatukan keluarganya.

Eksternalisasi yang dipahami adalah masyarakat beradaptasi dengan konsep gender yang berlainan dengan konsep gender konvensional. Keterangan dari para informan, lahir dan hidup dengan pengetahuan sesuaikonsep gender maskulin konvensional sesuai dengan budaya Indonesia. Konsep gender maskulinitas konvensional kemudian dijadikan sebagai acuan pandangan hidup dalam mendefinisikan gender pada kehidupan bermasyarakat.

Informan 8 mengatakan bahwa konsep "laki-laki cantik" lebih kepada atraktif bukan karena memakai make up layaknya wanita. Kulit putih adalah ciptaan Tuhan, tidak semua lakilaki Korea yang memiliki paras mulus adalah hasil operasi plastik. Informan 7 mengatakan bahwa make up tidak ada hubungannya dengan orientasi seksual seseorang. “...sejak kecil kita didoktrin bahwa cowok macho itu harus yang sangar, tatoan, merokok gara-gara iklan. Orang tua juga mengajarkan bahwa laki-laki itu tidak boleh nangis, atau memakai baju berwarna pink..." (Informan 7, Juli 2020)

Potret laki-laki yang ditampilkan media mengacu pada konsep hegemoni maskulinitas. Berbagai iklan rokok berlomba menampilkan sisi maskulinitas laki-laki ke dalam bentuk Cowboy yang digambarkan dengan laki-laki yang kasar, penuh debu dan berani menantang bahaya. Preferensi warna juga menjadi pembeda gender dalam masyarakat. Lakilaki identik dengan warna-warna gelap seperti hitam, biru tua, coklat tua. Sedangkan wanita identik dengan warna-warna cerah dan pastel seperti merah muda, biru muda, dan ungu.

Informan 1 mengatakan bahwa pemakaian make up yang dilakukan oleh para idol Korea ataupun model merupakan hal yang lumrah karena sesuai dengan budaya Korea, dan tuntutan pekerjaan sebagai public figure agar selalu terlihat menyenangkan untuk dipandang.

\section{Objektivasi Soft masculinity}

Objektivasi ini adalah sebuah interaksi dengan dunia intersubjektif. Perspektif masyarakat memandang gender dan budaya sebagai dua entitas yang berbeda. Hal ini memungkinan munculnya pemaknaan baru tentang konsep gender maskulinitas tersebut.

Informan 8 yang mengatakan bahwa dirinya mengalami pandangan berbeda mengenai konsep maskulin setelah menggandrungi grup idol asal Korea Selatan, BTS. "...kalau kita bandingkan artis barat kaya Westlife ya yang sama-sama boyband, memang ada bedanya sama idol korea semacam BTS. Kalau artis barat itu, ya menarik, mereka ganteng, tapi terkesan cuek aja sama fans. Kalau artis korea, mereka ada kesan sopan, mungkin karena sama-sama Asia dan budaya Asia kan memang kaya gitu sopannyabeda..."(Informan 8, Agustus 2020) Kesan lembut (tender) dan sopan (polite) tidak hanya diutarakan oleh informan 8 . Informan 2, informan 6, dan informan 7 mengemukakan pandangan serupa bahwa ada kaitan antara budaya Asia yang terkenal menjunjung nilai sopan santun. "...Korea itu kan sangat menjunjung tinggi kesopanan ya. Meskipun apapun status sosialnya, mereka tahu harus bicara dengan Bahasa yang sopan kalau ketemu dengan orang yang lebih tua. Itu sih yang sering ditampilkan. Misalnya bukan tokoh cowok yang selalu hormat dengan orang tuanya, ataupun orang yang dituakan misalnya bos, kakek nenek, kakak. Jadi udah ganteng, perilakunya juga positif, nggak kasar..." (Informan 6, Juli 2020) 
"...mau macho atau nggak macho sama aja asalkan mereka punya manner, well educated. Kalau dulu melihat boyband bule seperti Westlife, kita memuja-muja karena mental kita masih mental terjajah yang bilang bahwa orang barat itu lebih baik dari kita. Media massa juga terlena dengan sistem patriarkis jadi imej cowok manly dan macho stuck aja di situ terus..." (Informan 7, Juli 2020) Pemerintah Korea Selatan menggunakan Hallyu sebagai aspek penting dalam melakukan "nation branding" dengan meluncurkan program "K-Culture" (Lee et al., 2017). Hal ini berkaitan dengan konsep budaya campuran yang diusung oleh pemerintah Korea Selatan. Nilai - nilai budaya Korea Selatan yang rendah hati, menjunjung tinggi sopan santun dipadukan dengan kebebasan berekspresi yang diadopsi dari negara Barat. Perpaduan ini menghasilkan hybrid culture dan tercermin dalam representasi budaya korea yang disajikan melalui drama, musik, makanan, dan bahasa. Tidak hanya diterima di Kawasan Asia, namun juga diterima secara global di Amerika dan Eropa.

Konsep Hybrid Culture oleh pemerintah Korea Selatan tersebut dianggap sebagai upaya ekspansi imperalisme budaya berupa aliran multiarah produk budaya ke negara dominan.

Pandangan Informan 3 dan informan 4 mengatakan bahwa citra laki-laki Korea yang ditampilkan melalui serial drama menunjukkan kharisma laki-laki sesungguhnya, walaupun yang ditampilkan adalah sosok laki-laki klimis, berpakaian necis, rapi dan terlihat memiliki sikap gentle terhadap wanita. "...laki-lakiidealnggakharusyangbrewokan, atau berotot. Asal dia mau bertanggung jawab. Saya suka liat penampilan Hyun Bin di drama "Crash Landing on You (CLOY)". Tokoh yang dimainkan adalah perwira militer tetapi mukanya mulus, rambut klimis rapi, sikapnya lembut sama aktris pemeran utamanya. Walaupun begitu tetap ada wibawanya sebagai anggota militer, tetap tegas. Walaupun tidak punya perawakan yang kekar seperti bintang film action Hollywood, aktor-aktor korea yang juga bermain di drama aksi menurut saya tetap terlihat macho, tetap manly, dengan cara mereka sendiri. Mereka tetap punya kharisma. Ada kesan cowok baik-baik gitu. Kalem. Nggak macam-macam..." (Informan 3, Juni 2020) "...tetap kelihatan cowok banget sih. Meskipun kulit mereka mulus kaya porselen, bibir merah merona, saya tetap bisa bilang mereka itu ganteng dan cool. Misalnya aktor Ji Chang Wook, di drama dan di keseharian, memang cowok banget. Ada pesona sendiri. Pesona sebagai lakilaki maksudnya..." (Informan 4, Juli 2020) Pada proses objektivasi ini seringkali tidak disadari bahwa semua perilaku yang disadari ataupun tidak disadari ini merupakan buatan manusia yang sedang dalam proses untuk "menjadi". Konstruksi sosial berperan untuk mendorong konsep gender dan budaya untuk kemudian terwujud menjadi sebuah tindakan. Ini yang disebut sebagai institusional.

Awal kemunculan sebuah konsep selalu menimbulkan pertanyaan bahkan dianggap sebagai "tandingan" dari yang konsep lama. Informan 7 berpendapat bahwa dirinya kurang setuju dengan pandangan bahwa "laki-laki cantik" adalah tandingan laki-laki macho. Pemikiran bahwa laki-laki yang terlihat macho adalah laki-laki tulen didasarkan pada sistem patriarkis. Pemikiran seperti itu yang merusak mental laki-laki karena ditekan dengan konsep maskulinitas hegemoni untuk bisa diterima oleh masyarakat. Hal ini membuat laki-laki tidak bisa bebas untuk mengekspresikan diri.

Informan 7 mengatakan bahwa jika brand ambassador laki-laki tidak terlalu berpengaruh pada konsumen laki-laki karena sebenarnya lebih menyasar pada penggemar wanita dari aktor atau grup idol tersebut seperti grup idol BTS yang dipakai sebagai brand ambassador masker wajah "Mediheal". Para member BTS pernah menunjukkan tutorial memakai masker kecantikan "Mediheal" yang mayoritas penggemar BTS adalah wanita. Informan 7 menambahkan bahwa produk skincare seperti masker wajah belum popular digunakan pria di Indonesia. Ketidakpopuleran masker wajah di kalangan lak-laki juga mungkin disebabkan oleh pengaruh budaya lokal yang kuat. 
Informan 2 mengatakan bahwa sudah waktunya untuk pria dan wanita memiliki kulit yang sama-sama sehat bukan karena permasalahan gender. Informan 5, yang juga melakukan perawatan wajah, mengatakan bahwa laki-laki yang merawat diri berarti memiliki otonomi terhadap diri sendiri. Lakilaki sebagai individu sadar bahwa perlu merawat diri, bukan karena ingin terlihat cantik seperti wanita. Tidak ada hubungan dengan orientasi seksual ataupun gender.

\section{Internalisasi Soft Masculinity}

Internalisasi adalah proses individu melakukan identifikasi diri di dalam dunia sosiokultural. Identifikasi diri menjadi mudah di era tenologi media yang tinggi. Anak muda dengan sangat mudah mengasosiakan dirinya dengan idola favoritnya. Informan 5 mengatakan bahwa dirinya menjadikan para idol sebagai referensi dalam konteks penampilan sehari-hari. "...kalau sehari-hari saya memang menjadikan idol korea sebagai referensi dalam hal penampilan. Saya suka karena mereka kelihatan rapi dan sopan aja. Seperti idola saya, Nickhun, penampilannya preppy, jadi kelihatan classy. Jaman sekarang sepertinya kalau cowok harus keliatan macho berotot, nggak banget. Ya, apa adanya aja. Bukan cuma karena ikut-ikutan tren. Cowok jaman sekarang sudah paham bahwa merawat diri itu perlu..." (Informan 5, Juli 2020)

Penafsiran terhadap sebuah tindakan bukan lagi didasarkan pada konsep atau pemahaman terdahulu. Kesadaran sebuah ideologi atau konsep terwujud menjadi sebuah tindakan nyata. Masyarakat sadar tujuan dan manfaat tindakan tersebut.

Informan 8 menuturkan bahwa saat ini menjadi sangat normal dan wajar mengenai kemunculan produk perawatan wajah yang menggunakan laki-laki sebagai brand ambassador. "...mungkin karena cowok, terus sekarang mereka (cowok) lebih sering jadi brand ambassador produk kecantikan terutama skin care di korea sana. Kalau menurut saya sih ya, wajar aja, mungkin karena pasarnya juga ada di Korea sana..." (Informan 8, Agustus 2020) “...sebelum booming produk perawatan Korea, adik laki-laki saya sering pakai skincare punya saya seperti Pond's, atau SR12, tapi mereka belum mau pakai masker..." (Informan 7, Juli 2020)

Popularitas produk perawatan wajah tidak lepas dari product placement dalam setiap drama korea. Hampir semua drama korea merupakan wadah untuk mempromosikan produk perawatan wajah. Drama "Encounter" (2018) mempromosikan produk make up dari Sulwhasoo karena sang aktris Song Hye Kyo, adalah brand ambassador produk tersebut. Drama "Memories of Alhambra" (2018) memasukkan produk kecantikan Mamonde dengan alasan sama yaitu aktris pemeran utama, Park Shin Hye, merupakan brand ambassador dari Mamonde.

Informan 1 mengatakan bahwa pemakaian make up untuk lakilaki dirasa tidak menjadi masalah. "... rasanya sekarang makin banyak cowok yang grooming dirinya (perawatan) entah itu pakai masker, lip balm. Mungkin karena Korean wave tadi, dimana budaya korea sekarang cepat tersebar lewat media, apalagi di internet. Jadinya banyak juga brand-brand kecantikan yang sekarang nggak cuma targetin perempuan, tapi ke laki-laki juga. Mereka juga punya Korean Beauty Standar juga. Hasilnya semua orang jadinya ikut juga..." (Informan 1, Juli 2020) Informan berpendapat penampilan mereka (para idol Korea) dikarenakan tuntutan pekerjaan yang mengharuskan mereka untuk berpenampilan seperti itu. Korea dikenal dengan standar kecantikan. Memiliki wajah sempurna menjadi obsesi bagi Sebagian besar warga Korea Selatan sehingga tindakan bedah plastik adalah hal yang biasa dilakukan. Wisata medis bedah plastik juga dijadikan sebagai salah satu daya tarik wisata, sehingga tidak sedikit wisatawan asing, termasuk Indonesia, datang ke Korea untuk melakukan bedah plastik. Informan 1 menambahkan bahwa penggunaan idola laki-laki sebagai brand ambassador tidak lepas dari usaha untuk meraup keuntungan. 


\section{Citra laki-laki lembut (tenderness)} dipromosikan oleh Korea Selatan melalui representasi media terutama dalam drama televisi dan musik. Informan 2 mengatakan bahwa sejak mengkonsumsi budaya Asia, ada perubahan sudut pandang mengenai standar ideal laki-laki. Ketika remaja mengidolakan bule, sementara saat ini (dewasa) lebih menyukai laki-laki Asia. "...waktu masih smp, mungkin karena media juga, sering nonton serial barat jadi saya ideal saya ya orang kulit putih. Kadang suka mengkhayal kalau suatu saat ingin punya pacar bule. Tapi semakin dewasa saya lebih sering konsumsi konten hiburan dari negara lain termasuk Indonesia, juga dramadrama asia, saya merasa ya cowok bule bukan cowok yang paling ganteng sedunia. Standar ideal saya berubah. Saya jadi lebih suka laki-laki Asia, mungkin karena saya orang Asia juga, kedekatan budaya, dan warna kulit..." (Informan 2, Juli 2020)

Ke-Asia-an juga menjadi salah satu alasan utama tingginya popularitas Korean Wave di negara-negara Asia. Manusia cenderung menggunakan referensi dari budaya terdekat. Orang Asia cenderung untuk menjadikan budaya Asia sebagai referensi dalm mencari jati diri.

Hal serupa dikemukakan oleh informan 8 dengan membandingkan dominasi grup boyband barat seperti Westlife yang popular di akhir 90an.

“...kan, dulu pecinta Westlife juga suka sama bintang Bollywood, sekarang entah kenapa jujur lebih suka sama artis Korea. Menurut saya mereka lebih keren, lebih enerjik, lebih ke anak muda gitu. Meskipun mereka dance, joget tapi nggak kaya cewek kok gerakannya justru keren dan cowok banget..." (Informan 8, Agustus 2020)

Pernyataan ini memperkuat asumsi bahwa pengaruh dominasi budaya barat yang ada sejak era kejayaan serial televisi di awal 90an perlahan telah bergeser. Ras Asia dipandang sebagai warga kelas dua. Di Amerika, lakilaki Asia dianggap kurang macho jika dibandingkan dengan laki-laki kaukasia.
Kesadaran atas tindakan tersebut menjadi pembiasaan atau habitualisasi. Tindakan rasional dan memiliki tujuan ini kemudian tidak memerlukan lagi penafsiran. Hal ini dikarenakan tindakan tersebut secara kognitif dan evaluatif dimiliki oleh masyarakat. Tindakan ini kemudian menjadi sebuah tindakan mekanis yang dilakukan secara otomatis dalam kehidupan sehari-hari.

Perubahan konsumsi media dengan representasi budaya di dalamnya, merubah sudut pandang manusia. Informan 2 menjelaskan bahwa perubahan konsumsi media memengaruhi persepsinya mengenai standar ideal laki-laki. Informan 7 menganggap media di masa lalu terlalu terlena dengan sistem patriarkis yang ada sehingga konsep hegemoni maskulinitas berada pada status quo yang tidak membiarkan laki-laki untuk bebas mengekspresikan identitas gender.

Informan 5 menyatakan saat ini laki-laki memiliki otoritas terhadap dirinya. Laki-laki tidak lagi terkekang dalam pandangan tradisional tentang konsep laki-laki maskulin. Informan 3, 4, dan 6 berpendapat sosok laki-laki ideal tidak lagi dinilai berdasarkan fisik, namun lebih pada kualitas yang ada dalam invidu berupa kelembutan sikap dan hati, sopan santun, dan pribadi humoris, ceria dengan tidak melupakan tanggung jawab laki-laki sebagai pelindung.

Pergeseran persepsi terjadi dengan cepat dikarenakan akses informasi yang mudah melalui teknologi media baru. Dampaknya adalah arus budaya menjadi sangat cair dikarenakan saat ini kehadiran media baru memungkinan manusia menjadi seorang produsen sekaligus konsumen dari konten pesan yang disajikan oleh media baru. (Tresnawati et al., 2019). Konsumsi budaya populer semakin meningkat dengan kehadiran fandom atau komunitas fans, tidak hanya musik tapi juga untuk drama korea.

Luthfina dan Irwansyah (2020) mengungkap bahwa media dan fandom berada dalam ekosistem yang sama, dimana media baru merupakan ruang baru yang digunakan fans sebagai tempat untuk mengekspresikan berbagai sudut pandang dalam kehidupan, termasuk di dalamnya ekspresi mengenai identitas gender. 
Gender selalu menjadi sebuah identitas yang dinegosiasikan. Konsep gender terkait dengan situasi dan kondisi dari budaya tempat individu itu berada. Çınar (2015) menegaskan bahwa gender adalah sebuah mekanisme "penampilan", "pertunjukan". Mekanisme ini yang merefleksikan pembatas dimana gender dapat diubah dan dinaturalisasi melalui peran gender yang subversif untuk menciptakan peran gender baru. Hal ini selaras dengan pendapat Barry (2018) bahwa laki-laki secara strategis memberi batasan pada bermacam performa gender pada tingkatan tertentu, tergantung pada sejauh mana tempat, kegiatan serta interaksi menghargai atau justru meremehkan performa laki-laki feminin.

Sun Jung (2011) memformulasikan peran gender baru, soft masculinity, ke dalam tiga karakteristik yaitu Tender Charisma, Purity, dan Politeness. Tender charisma dideskripsikan seorang laki-laki memiliki dua kualitas dalam dirinya yaitu ketegasan seorang laki-laki, dan kelembutan, kesensitifan yang sering diasosiasikan dengan kepribadian perempuan. Konsep hybrid ini dianggap sebagai tanda bahwa gagasan maskulinitas cenderung mengalami perubahan (Bridges, 2014). Perpaduan antara maskulinitas dan feminitas yang ditampilkan para aktor hallyu membentuk identitas baru sebagai standar ukur maskulinitas modern. Seseorang tidak bisa dikatakan maskulin hanya dari segi fisik saja namun juga ada unsur lain seperti sikap dan perilaku (Ayuningtyas, 2017).

Jeong et al. (2017) menyatakan bahwa media sebagai salah satu agen sosialiasi budaya berperan penting dalam menyebarkan nilai-nilai dan pergeseran. Sirkulasi gelombang Korea di lanskap media sosial meningkatkan dan ditingkatkan oleh praktik budaya partisipatif. Penelitian Triartanto et al. (2020) menyatakan sebaran nilai budaya asing dalam hal ini budaya Korea, disisipi oleh produsen produk dengan target sasaran para penggemar fanatik selebritas Korea.
Penelitian Jin \& Yoon (2016) mengatakan bahwa banyak responden menikmati budaya pop Korea melalui konten buatan pengguna (usergenerated content atau UGC), termasuk YouTube. Teknologi media baru berperan sebagai agen sosialisasi menyebabkan konsep soft masculinity terus berkembang seiring dengan perubahan budaya di masyarakat (Jeong et al., 2017; Jin, 2019; Jin \& Yoon, 2016; Jung, 2019; Khai \& Wahab, 2017; Lee et al., 2017; Lee et al., 2020; Nurhadi, 2018; Oh \& Lee, 2013). Dalam drama Korea, tidak jarang terdapat scene dimana tokoh laki-laki menangis dan disorot dalam tampilan close-up dan kebanyakan karakter laki-laki dalam Korea direpresentasikan sebagai laki-laki yang memiliki kekuasaan, kuat, kaya raya, misalnya seorang pengusaha kaya (Chaebol), polisi, pendekar, bahkan raja (Khai \& Wahab, 2017).

Purity sebagai karakteristik kedua dari soft masculinity juga dipahami oleh para informan sebagai ketulusan, keluguan, di mana lakilaki tidak melulu memandang wanita sebagai objek seks semata. Penelitian oleh Fauzi dan Nugroho (2020) menjelaskan bahwa hubungan antar laki-laki berupa kontak fisik dapat diterima walaupun dalam konteks budaya lokal dianggap masih kurang pantas Hubungan sesama lelaki terdapat istilah Bromance yang merupakan kepanjangan dari brother romance, yang menggambarkan bahwa kedekatan fisik lakilaki tidak melulu diartikan sebagai kedekatan romantis layaknya dalam hubungan lawan jenis tetapi lebih pada kasih sayang antara saudara laki-laki, dimana dalam budaya Korea ini adalah hal yang wajar (Fauzi \& Nugraha, 2020).

Karakteristik purity (innocent) juga sering muncul dalam bentuk Aegyo. Aegyo merupakan gestur dan gaya ucapan dalam budaya Korea yang biasanya dilakukan oleh anak-anak atau remaja perempuan agar terlihat imut atau lucu di mata orang lain (Fathinah et al., 2017). Bukan hanya anak-anak, tetapi 
untuk orang dewasa terutama laki-laki sangat biasa dilakukan. Hal ini yang kemudian menimbulkan persepsi purity atau innocent layaknya anak-anak pada citra laki-laki Korea.

Karakteristik ketiga adalah politeness. Karakteristik ini mendobrak stereotipe lakilaki pada masa lalu laki-laki digambarkan sebagai pribadi yang kasar dan cuek. Politeness didasarkan pada kepribadian Bae Yong Joon yang sangat menghormati penggemarnya. Seperti halnya para anggota grup Idol BTS yang menyebut bahwa fans adalah keluarga besar dan bahwa BTS tidak bisa besar tanpa penggemar Sistem masyarakat di Indonesia menganut sistem patriarkis sehingga konsep androgynous belum dikenal luas oleh masyarakat di Indonesia. Kemunculan konsep maskulinitas baru menyebabkan definisi gender kembali ditelaah untuk mendapatkan pemahaman baru. Adaptasi juga dilakukan terhadap sikap dan nilai baru seperti pandangan bahwa seorang laki-laki yang melakukan perawatan diri tidak kemudian dimasukkan ke dalam kategori sebagai kewanita-wanitaan atau banci. Kesadaran konsep soft masculinity tercipta sehingga muncul tindakan sebagai tanda bahwa konsep tersebut direstui oleh masyarakat. Jika melihat saat ini banyak produk-produk kecantikan baik make up ataupun perawatan wajah yang menggunakan model laki-laki, utamanya produk-produk kecantikan dan perawatan wajah asal Korea Selatan (Maliangkay, 2013).

Output dari internalisasi berupa sudut pandang baru yaitu soft masculinity. Persepsi baru ini menjadi sebuah realitas sosial yang kemudian diresapi oleh anggota masyarakat tersebut kemudian menjadi sebuah persepsi personal baru. Ini yang diungkapkan oleh Nurhadi (2018) sebagai transformasi dari realitas sosial menjadi realitas subjektif. Hal ini terjadi secara berulang di mana media berperan dalam menyebarkan nilai-nilai kebudayaan yang menginternal sehingga konsep soft masculinity menjadi sebuah realitas subjektif yang kemudian dieksternalisasikan ke dalam kehidupan bermasyarakat sehingga lama-kelamaan soft masculinity menjadi sebuah realitas objektif yang tidak bisa diabaikan dan menjadi referensi dalam mendefinisikan standar ideal laki-laki masa kini.

Hasil penelitian ini memperkuat asumsi mengenai hubungan antara media dengan perubahan budaya. Lestari dan Dwijayanti (2020) menyatakan bahwa meski mengkhawatirkan, namun internalisasi realitas objektif ke dalam realitas subjektif berupa privatisasi pengetahuan dan nilai-nilai simbol merupakan hasil interaksi antara media baru dengan individu. Pada penelitian ini generasi Y sebagai individu merupakan khalayak yang aktif dalam menafsirkan interaksi simbolik yang terjadi antara media, budaya, dan masyarakat. Media sebagai wadah untuk negosiasi ideologi-ideologi baru. Penerimaan nilai-nilai asing seperti budaya Korea dan ideologi maskulinitas baru, dilakukan melalui tiga tahap dialektis sehingga stereotipe hegemoni laki-laki dipatahkan. Konsep soft masculinity sebagai hasil akhir konstruksi sosial menjelma menjadi sebuah realitas subjektif dari masing-masing individu. Realitas ini kemudian disetujui dan diterima oleh masyarakat Indonesia yang memiliki akar kuat pada tradisi patriarki.

\section{Simpulan}

Hasil penelitian ini menyimpulkan bahwa persepsi generasi $\mathrm{Y}$ sebagai digital natives, terhadap konsep maskulinitas mengalami pergeseran makna. Pemaknaan baru tersebut diproduksi melalui tiga momen dialektika, yaitu: Eksternalisasi, obyektivitasi, dan internalisasi. Eksternalisasi sebagai tahap dasar melihat interaksi individu dengan lingkungan sosiokultur, termasuk produk-produk sosial berupa konsep gender. Pada tahap ini, para informan melakukan proses adaptasi terhadap ide, konsep dan nilai baru dari soft masculinity. Objektivasi merupakan proses dimana individu menempatkan ide konsep dan nilai dari soft masculinity sebagai realitas yang terbentuk 
di luar dirinya. Pada tahap ini, konsep gender dipandang sebagai sebuah realitas objektif yang terbentuk melalui interaksi intersubjektif. Tahap akhir, internalisasi, merupakan proses penarikan kembali realitas objektif ke dalam kesadaran subjektif individu. Konsep soft masculinity dikonsumsi terus menerus secara sadar sehingga dipahami sebagai makna baru dari masculinity dan menjadi sebuah realitas objektif yang dijadikan acuan dalam kehidupan bermasyarakat.

Hal ini menjelaskan bahwa bagi generasi Y, konsep maskulinitas tradisional dianggap sudah kadaluarsa. Maskulinitas dipandang sebagai sebuah konsep yang terus berubah seiring dengan dinamisme manusia. Perkembangan teknologi informasi juga dilihat sebagai pemicu cairnya arus transcultural yang direpresentasikan dan dinegosiasikan melalui konten-konten media baru. Konsep Soft masculinity bersifat fleksibel dimana konsep tersebut berubah di masa depan sesuai dengan perkembangan budaya masyarakat. Kontribusi penelitian ini berupa rekomendasi konsep baru terkait maskulinitas kepada generasi Y agar memiliki perspektif baru dalam memandang konsep gender di masyarakat.

\section{Ucapan Terima Kasih}

Penulis mengucapkan Terima kasih kepada Universitas Mercu Buana yang telah mendanai riset ini. Juga kepada para informan yang sudah bersedia untuk diwawancara via daring.

\section{Daftar Pustaka}

Ainslie, M. J. (2017). Korean soft masculinity vs. Malay hegemony: Malaysian masculinity and Hallyu fandom. Korea Observer, 48(3), 609-638. Akhmad, R. A., Unde, A. A., \& Cangara, H. (2018). Fenomenologi Penggunaan Televisi Dan Media Sosial Dalam Menyikapi Budaya Pop Korea Di Kalangan Remaja Makassar. KAREBA : Jurnal Ilmu Komunikasi, 16-22. https://doi.org/10.31947/kareba.v7i1.5246
Alam, S., \& Nyarimun, A. J. (2017). Musik K-Pop sebagai Alat Diplomasi dalam Soft Power Korea Selatan. International \& Diplomacy, 3(1), 26. Appadurai, A. (2016). The Academic Digital Divide and Uneven Global Development. PARGC Press, 15. Ayuningtyas, P. (2017). Indonesian Fan Girls' Perception towards Soft Masculinity as Represented By K-pop Male Idols. Lingua Cultura, 11(1), 53-57. Baker, P., \& Levon, E. (2016). 'That's what I call a man': Representations of racialised and classed masculinities in the UK print media. Gender and Language, 10(1), 106-139. https://doi.org/10.1558/genl.v10i1.25401

Barry, B. (2018). (Re)Fashioning Masculinity: Social Identity and Context in Men's Hybrid Masculinities through Dress. Gender \& Society, 32(5), 638-662. https:// doi.org/10.1177/0891243218774495

Bridges, T. (2014). A Very "Gay" Straight?: Hybrid Masculinities, Sexual Aesthetics, and the Changing Relationship between Masculinity and Homophobia. Gender \& Society, 28(1), 58-82. https://doi. org/ $10.1177 / 0891243213503901$

Bridges, T., \& Pascoe, C. J. (2014). Hybrid Masculinities: New Directions in the Sociology of Men and Masculinities: Hybrid Masculinities. Sociology Compass, 8(3), 246-258.https://doi.org/10.1111/soc4.12134

Çınar, B. (2015). A Performative view of gender roles: Judith butler. International Journal of Media Culture and Literature, 1(1), 153-160.

Connell, R. (2016). Masculinities in global perspective: Hegemony, contestation, and changing structures of power. Theory and Society, 45(4), 303-318. https:// doi.org/10.1007/s 11186-016-9275-x

Coston, B. M., \& Kimmel, M. (2012). Seeing Privilege Where It Isn't: Marginalized Masculinities and the Intersectionality of Privilege. Journal of Social Issues, 68(1), 97-111. https://doi. org/10.1111/j.1540-4560.2011.01738.x 
Elaskary, M. (2018). The Korean Wave in the Middle East: Past and Present. Journal of Open Innovation: Technology, Market, and Complexity, 4(4), 51. https://doi.org/10.3390/joitmc4040051

Fathinah, E., Priyatna, A., \& Adji, M. (2017). Maskulinitas Baru Dalam Iklan Kosmetik Korea: Etude House Dan Tonymoly. Patanjala: Jurnal Penelitian Sejarah dan Budaya, 9(2), 213. https:// doi.org/10.30959/patanjala.v9i2.3

Fauzi, E. P., \& Nugraha, R. P. (2020). Reception Analysis Of Bromance In "Run Bts!" Variety Show On Vlive Video Platform. IJRDO Journal of Social Science and Humanities Research (ISSN: 2456-2971), 5(4), 114-123.

Fibrianto, A. S., Asrori, M. I., Mahardiansyah, D., Anggraini, L. M., Lailani, A. T. U., Azizah, S. N., \& Trianjaya, A. (2020). Analysis of Globalization Phenomena: Forms of K-Pop Cultural Fanaticism Among Students (Case Study of Sociology Student at Universitas Negeri Malang). Proceedings of the International Conference on Social Studies and Environmental Issues (ICOSSEI 2019). International Conference on Social Studies and Environmental Issues (ICOSSEI 2019), Kota Malang, Indonesia. https://doi.org/10.2991/assehr.k.200214.058

Friedman, L. (2017). Millennials And Gender Fluidity-What Smart Brands Are Doing And Why. Forbes. https://www.forbes. com/sites/laurenfriedman/2017/11/28/ millennials-and-gender-fluidity-whatsmart-brands-are-doing-and-why/ Itulua-Abumere, F. (2013). Understanding Men and Masculinity in Modern Society. Open Journal of Social Science Research, 1(2), 42. https://doi.org/10.12966/ojssr.05.05.2013

Jang, W., \& Song, J. E. (2017). The Influences of K-pop Fandom on Increasing Cultural Contact. Korean Association of Regional Sociology, 18(2), 28.
Jeong, J. S., Lee, S. H., \& Lee, S. G. (2017). When Indonesians routinely consume Korean pop culture: Revisiting Jakartan fans of the Korean drama Dae Jang Geum. International Journal of Communication, 11, 2288-2307. Jin, D. Y. (2019). Transnationalism, cultural flows, and the rise of the Korean Wave around the globe. International Communication Gazette, 81(2), 117-120. https://doi.org/10.1177/1748048518802911

Jin,D.Y.,\&Yoon,K.(2016). Thesocialmediascape of transnational Korean pop culture: Hallyu 2.0 as spreadable media practice. New Media \& Society, 18(7), 1277-1292. https://doi.org/10.1177/1461444814554895 Jung, H. (2019). Agenda-setting in the realm of popular culture: The case of the Korean Wave in East Asia. Global Media and Communication, 15(3), 361-377. https:// doi.org/10.1177/1742766519872782 Jung, S. (2011). Korean masculinities and transcultural consumption: Yonsama, Rain, Oldboy, K-Pop idols (Vol. 1). Hong Kong University Press. Juniman, P. T. (2017). “Gender Fluidity” di Kasus Zayn-Hadid Tak Sekadar soal Busana. CNN Indonesia. https://www.cnnindonesia.com/ gaya-hidup/20170715170426-277-228125/ gender-fluidity-di-kas us - zaynhadid-tak-sekadar-soal-busana Katz-Wise, S. L. (2020). Gender fluidity: What it means and why support matters. Harvard Health Blog. https://www.health.harvard. edu/blog/gender-fluidity-what-it-meansand-why-support-matters-2020120321544

Khai, S. W., \& Wahab, J. A. (2017). Prettiness as a Shield: The Romantic Perpetuation of Patriarchy through the Representation of Pretty Boy in Popular Korean Dramas in Malaysia. Media Watch, 8(3). https:// doi.org/10.15655/mw/2017/v8i3/49153 
Kusuma, A., Putri Purbantina, A., Nahdiyah, V., \& Khasanah, U. U. (2020). A Virtual Ethnography Study: Fandom and Social Impact in Digital Era. ETNOSIA : Jurnal Etnografi Indonesia, 5(2), 238-251. https:// doi.org/10.31947/etnosia.v5i2.10898

Kusuma, G. D., Prayudi, P., \& Rochayanti, C. (2020). Konstruksi Realita Sosial City Branding Magelang Kota Sejuta Bunga (MKSB). Jurnal Ilmu Komunikasi, 17(3), 314. https://doi.org/10.31315/jik.v17i3.3783

Kwon, S. H., \& Kim, J. (2014). The cultural industry policies of the Korean government and the Korean Wave. International Journal of Cultural Policy, 20(4), 422-439. https:// doi.org/10.1080/10286632.2013.829052

Lee, S. H., Kwak, G.-H., Kim, H.-S., \& Lee, K.-S. (2017). The Effect of the Korean Wave on Malaysian University Students' Perception. Culinary Science \& Hospitality Research, 23(1), 79-83. https:// doi.org/1 0.20878/CSHR.2017.23.1.009

Lee, S., \& Nornes, A. M. (2015). Hallyu 2.0: The Korean Wave in the age of social media. University of Michigan Press. Lee, Y. L., Jung, M., Nathan, R. J., \& Chung, J.-E. (2020). Cross-National Study on the Perception of the Korean Wave and Cultural Hybridity in Indonesia and Malaysia Using Discourse on Social Media. Sustainability, 12(15), 6072. https://doi.org/10.3390/su 12156072

Lestari, C. A., \& Dwijayanti, R. I. (2020). Kecakapan Literasi Media di Kalangan Generasi Milenial. Jurnal Ilmu Komunikasi, 18(1), 48. https:// doi.org/10.31315/jik.v18i1.2781

Louie, K. (2012). Popular Culture and Masculinity Ideals in East Asia, with Special Reference to China. The Journal of Asian Studies, 71(4), 929-943. https:// doi.org/10.1017/S0021911812001234
Luthfina, S., \& Irwansyah, I. (2020). Studi Fenomenologi: Penggunaan Aplikasi Weverse Shop oleh ARMY. Jurnal Ilmu Komunikasi, 18(3), 324. https:// doi.org/10.31315/jik.v18i3.3527 Maliangkay, R. (2013). Catering to the female gaze: The semiotics of masculinity in Korean advertising. Situations, 7(1), 43-61.

Messner, M. A. (2007). The Masculinity of the Governator: Muscle and Compassion in American Politics. Gender \& Society, 21(4), 461-480. https://doi. org/10.1177/0891243207303166

Morissan, Wardhani, A. C., \& Hamid, F. (2015). Teori komunikasi massa: Media, budaya, dan masyarakat. Bogor: Penerbit Ghalia Indonesia.

Nisrina, D., Widodo, I. A., Larassari, I. B., \& Rahmaji, F. (2020). Dampak Konsumerisme Budaya Korea (Kpop) Di Kalangan Mahasiswa Fakultas Ilmu Sosial Universitas Negeri Malang. Jurnal Penelitian Humaniora, 21(1), 78-88. https:// doi.org/10.23917/humaniora.v21i1.8085

Nurhadi, Z. F. (2018). Model Komunikasi Sosial Laki-Laki Feminim. Jurnal Ilmu Komunikasi, 16(3), 10. https:// doi.org/10.31315/jik.v16i3.3208 Oh,I., \& Lee,H. (2013). Mass Media Technologies and Popular Music Genres: K-pop and YouTube. Korea Journal, 53(4), 34-58. https://doi.org/10.25024/KJ.2013.53.4.34

Oh, I., \& Lee, H.-J. (2014). K-pop in Korea: How the Pop Music Industry Is Changing a PostDevelopmentalSociety.Cross-Currents: East Asian History and Culture Review, 3(3), 7293. https://doi.org/10.1353/ach.2014.0007 Prihantoro, E., Damintana, K. P. I., \& Ohorella, N. R. (2020). Self Disclosure Generasi Milenial melalui Second Account Instagram. Jurnal Ilmu Komunikasi, 18(3), 312. https://doi.org/10.31315/jik.v18i3.3919 
Putri,A. S. M., \& Mintarsih,A. R. (2020). Bangtan Sonyeondan In America: Soft Masculinity Performance And Audience Response. International Review of Humanities Studies. https://doi.org/10.7454/irhs.v0i0.230

Ratnasari, E., Sumartias, S., \& Romli, R. (2020). Penggunaan Message Appeals dalam Strategi Pesan Kampanye Anti Kekerasan Berbasis Gender Online. Jurnal Ilmu Komunikasi, 18(3), 352. https://doi.org/10.31315/jik.v18i3.3844

Santoso, P. (2016). Konstruksi Sosial Media Massa. AL-BALAGH: Jurnal Komunikasi Islam, 1(1), 19. Sen, K., \& Hill, D. (2011). Politics and the Media in Twenty-First Century Indonesia: Decade of Democracy. Routledge \& CRC Press.

Song, K. Y., \& Velding, V. (2020). Transnational Masculinity in the Eyes of Local Beholders? Young Americans' Perception of K-Pop Masculinities. The Journal of Men's Studies, 28(1), 3-21. https:// doi.org/10.1177/1060826519838869

Sulistiyo, P. A., Hubeis, A. V., \& Matindas, K. (2016). Komunikasi Gender Dan Hubungannya Dengan Kepuasan Kerja Karyawan (Gender Communication Related Employees Job Satisfaction). Jurnal Komunikasi Pembangunan, 14(2). https://doi.org/10.46937/14201613767

Tresnawati, Y., \& Ibrahim, N. F. BT. (2020). Search Engine Mapping on Media Usage (Among Korean and Indonesian Users). International Journal of English Literature and Social Sciences, 5(5), 1451-1459. https://doi.org/10.22161/ijels.55.19 Tresnawati, Y., Rahayu, M., \& Husen, M. (2019). Tinderand Impact on Personal and Social Life. International Conference on Psychology and Communication 2018(ICPC 2018), 230-246.

Triartanto, Y., Suryanto, A. D., \& Mutiah, T. (2020). Diseminasi Budaya Pop Televisi Dan Celebrity Branding Pada Iklan E-Commerce. Global Komunika: Jurnal Ilmu Sosial Dan Ilmu Politik, 1(2), Article 2. Veissière, S. P. L. (2018). "Toxic Masculinity" in the age of \#MeToo: Ritual, morality and gender archetypes across cultures. Society and Business Review, 13(3), 274-286. https://doi.org/10.1108/SBR-07-2018-0070

Velasco, J. C. (2020). Millennials as Digital Natives: Examining the Social Media Activities of the Philippine Y-Generation. Pertanika Journal of Social Sciences and Humanities, 28(3), 1939-1957. Wong, C. M. (2015, February 5). 50 Percent Of Millennials Believe Gender Is A Spectrum, Fusion's Massive Millennial Poll Finds | HuffPost [News Aggregator and blog]. HuffPost.Com. https:// www.huffpost.com/entry/fusionmillennial-poll-gender_n_6624200 Zakiah, K., Putri, D. W., Nurlimah, N., Mulyana, D., \& Nurhastuti, N. (2019). Menjadi Korean di Indonesia: Mekanisme Perubahan Budaya Indonesia - Korea. Mediator: Jurnal Komunikasi, 12(1), 90-101. https:// doi.org/10.29313/mediator.v12i1.3979 